\title{
Analysis of an Optimal Model for Liquidity Management of Financial Assets Using an Intelligent Scheduling Approach
}

\author{
Yi Zhou $\mathbb{D}^{1}{ }^{1}$ Weili Xia, ${ }^{1}$ and Shengping Peng $\mathbb{D}^{2}$ \\ ${ }^{1}$ School of Management, Northwestern Polytechnical University, Xi'an 710072, China \\ ${ }^{2}$ School of Economics and Management, Three Gorges University, Yichang 443002, China
}

Correspondence should be addressed to Shengping Peng; pengshengping@ctgu.edu.cn

Received 12 November 2021; Revised 1 December 2021; Accepted 4 December 2021; Published 21 December 2021

Academic Editor: Miaochao Chen

Copyright (C) 2021 Yi Zhou et al. This is an open access article distributed under the Creative Commons Attribution License, which permits unrestricted use, distribution, and reproduction in any medium, provided the original work is properly cited.

\begin{abstract}
This paper adopts the intelligent scheduling method to conduct an in-depth study and analysis on the optimization of financial asset liquidity management model, elaborates and analyzes the liquidity risk management theory of commercial banks, and reviews the progress of liquidity risk management research in domestic and foreign academia as the theoretical basis of this paper. After that, we analyze the liquidity risk management of Anhui Tianchang Rural Commercial Bank from both qualitative and quantitative levels and further review and analyze the problems and causes. Finally, the full research is summarized and reviewed, theoretical and practical insights are discussed and analyzed, and future liquidity risk management research priorities and directions are elaborated. Based on the analysis results, the problems of the bank in liquidity risk management are described one by one, and further deep-seated cause discovery is carried out to summarize the problems of liquidity risk management which exist in the bank's operation process due to the lack of liquidity risk management, unbalanced asset, and liability allocation, as well as weak emergency management capability, insufficient day-to-day liquidity monitoring, and lack of professional talents. For the problems and causes of the study, effective suggestions on how to strengthen the bank's liquidity risk management in multiple aspects are proposed. It is hoped that, by improving the bank's liquidity risk management and reducing the chance of liquidity risk occurrence, the bank's sustainable development can be enhanced, and it is also hoped that it can provide some reference for the liquidity risk management of similar rural small- and medium-sized financial institutions.
\end{abstract}

\section{Introduction}

Funds management is a comprehensive reflection of a securities firm's ability to allocate resources, operate, and develop healthily and sustainably. The initial population size of the algorithm is the same as 10 particles. PSO, GA, and $\mathrm{ABC}$ algorithm parameters are set as basic default parameters. At present, the issue of funds management and control has attracted widespread attention and importance. As an important component of the financial industry, the standardized and healthy development of securities firms is closely related to the stability of the securities market and the overall economy of society [1]. The funds held by securities companies include not only the capital funds from the participation of major shareholders but also the investment funds from social investors who randomly participate in market transactions, as well as the funds integrated by the company itself using financial leverage, which are important assets of securities companies throughout the decisionmaking and operation. Therefore, the need to strengthen the management and control of securities company funds is selfevident. In recent years, with the rise of Internet finance, diversified financial needs and market-oriented regulatory requirements have further driven the development of the securities industry. In response, a more market-oriented, legalized, and internationalized capital market has emerged [2]. In the face of a changing financial environment at home and abroad and a new round of technological industrial changes that are poised to take place, the securities industry has undertaken corresponding financial system reforms in line with the new development direction of greater openness, transparency, and health sustainability. Banks have made 
strong support for rural finance and provided a financing platform for the development of the rural economy, and the ability to manage liquidity risk directly affects the survival and development of banks and holds great significance for the stability of the rural financial environment and market.

Since finance companies are closely related to the development of the financial industry and the financial market, the characteristics and management modes of finance companies in different countries and so forth deeply influenced the local financial industry and financial policies, and there are great differences [3]. Many studies are still in the primary stage, and the research is not deep enough to fully meet the needs of finance companies in the process of centralized fund management practice and cannot achieve the perfect combination of industry and finance. In recent years, as the most advanced capital management mode, the finance company has been adopted by increased enterprise groups, and the reference of finance company capital management research has increased [4]. With the help of modern information systems, we will gradually establish a management mechanism with centralized fund management as the means.

This paper reviews the main research progress of liquidity risk management in domestic and foreign academia, starting from the analysis of the concepts, system framework, and classical theories of commercial banks' liquidity risk management; then, combining management theories and survey data, it deconstructs and analyzes the liquidity risk management of bank from both qualitative and quantitative levels and examines the problems and challenges faced by its management. After that, the paper focuses on the liquidity risk management practices and disposal experiences of regional small commercial banks according to the needs of the study to provide experience reference support for the optimization and improvement of liquidity risk management. Establish tiered response and handling standards for liquidity emergencies, and formulate corresponding contingency plans according to different tiered standards to improve the effectiveness and accuracy of emergency management.

\section{Current Status of Research}

Commercial banks have the following characteristics in terms of liquidity: first, because commercial banks have the characteristics of rigid business attributes of commitment to pay, their standards of liquidity requirements are more stringent; second, the purpose of commercial banks holding liquidity not only is to meet the need to meet payment obligations but also should be to avoid liquidation situations to the maximum extent possible [5]. The liquidity of commercial banks in the full sense of the word should also include the ability to provide the necessary adequate supply of funds for the conduct of various types of business [6]. Therefore, based on the above attributes, the definition of commercial banks' liquidity is the ability of commercial banks to obtain the necessary funds at a reasonable cost to effectively meet payments, transactions, and business expansion in the face of immediate and forward demand for funds [7]. Commercial banks should reasonably determine their liquidity risk appetite based on their business management practices and develop written liquidity risk management strategies, policies, and procedures accordingly [8]. Commercial banks' liquidity risk management strategies, policies, and procedures should cover their on- and offbalance sheet operations and all business units, branches, and subsidiaries that may have a significant impact on liquidity risk management and should include arrangements for liquidity risk management under normal and stress scenarios [9]. The issue of liquidity risk management is directly related to the survival and development of commercial banks and is an important long-term issue in the management of commercial banks; and how to build an effective internal governance structure for liquidity risk management to better identify, monitor, and manage the relevant risk profile is the key to good management [3].

With the rapid development of Internet consumer finance, research on topics related to Internet consumer finance has gradually attracted widespread attention from the academic community and has encouraged many scholars to conduct many insightful studies on related topics, and the relevant research results have provided important guidance for the practice of Internet consumer finance [10]. It is pointed out that commercial banks opening online services will likely face operational, security, legal, and reputational risks. The evolution from traditional banking to online banking indicates that the commercial banking service area has entered a new development field, but it also faces a new operation model that requires innovation in risk control mechanisms and methods [11]. At the same time, risk control will also change from a management approach based on selfregulation to one with more detailed content and more specific operations. The biological heuristic calculation is systematically studied, and the multiobjective optimization strategy is studied, and a variety of multigroup multiobjective root algorithms are proposed accordingly; according to the characteristics of the stock prediction problem, the wavelet denoising method is used to solve the problem with the LSTM model. From the perspective of financial products and services, the areas involved in consumer finance are analyzed in depth, and it is pointed out that consumer finance products and services should meet the needs of consumers in terms of credit, savings, and investment [12].

Firstly, a distributed decision investment risk management model is established and the RA algorithm is used to optimize the risk management model. Through experimental verification, the RA algorithm has faster convergence speed and stronger robustness in the risk management process and reflects the superiority of the RA algorithm. Firstly, the classical portfolio model is introduced and a novel triobjective return-risk-cost model is proposed according to the practical problem. The MPMORA algorithm is applied to portfolio asset allocation and the performance is compared with those of other algorithms. The experimental results show that MPMORA can solve complex multiconstraint problems optimally, with faster convergence and higher particle uniformity performance compared to existing classical multiobjective heuristic algorithms. 


\section{Analysis of a Liquidity Management Model for Financial Assets with an Intelligent Scheduling Approach}

3.1. Intelligent Scheduling Algorithm. The development of Internet consumer finance has significantly broadened the entry channels for providing consumers with consumer financial products and services. For example, consumers can easily and quickly access financial services and products that match their needs through shopping platforms, online platforms of financial institutions, and e-commerce platforms, and, based on Internet technology, such financial services and products will proliferate rapidly at a multiplicative rate. As the quality of financial services and products received by consumers is related to not only the consumers themselves but also other consumers accessing the network, the value of each consumer increases with the number of consumers accessing the network, which in turn facilitates the development of Internet consumer financial products and services. Network externalities are the basis on which Metcalfe's principle is built, and the demand for consumer financial services and products from different consumers in the network is heterogeneous [13]. Consumers' access to Internet consumer financial services or products is related to not only their own needs but also the needs of other consumers who access that Internet consumer finance network. Therefore, through the network link function of Internet consumer finance, consumer financial resources can be effectively allocated to consumers who access the network, which can effectively reduce the degree of mismatch in the allocation of consumer financial resources and achieve the Pareto optimal allocation of consumer financial resources. References for research on fund management of financial companies have also increased, and, with the ever-changing economic environment, research at this stage cannot meet the ever-changing market needs.

$$
E(s)=\lim _{m, n \longrightarrow \infty} \sum_{i=1}^{m} \sum_{j}^{n} w_{i j} s_{i}^{2} s_{j}+\lim _{n \longrightarrow \infty} \sum_{i=1}^{n} \beta_{i} s_{j} .
$$

With the application and popularity of the Internet, the integration of the Internet with traditional consumer finance has given rise to a new industry in the field of financial services, namely, Internet consumer finance. The innovation point for the emergence and development of Internet consumer finance comes mainly from the huge financial services innovation arising from solving the problem of consumers' financial needs. With the popularity of the Internet, many platforms can collect relatively comprehensive credit evaluation information on consumers from multiple dimensions, thus enabling a more objective "portrait" of consumers, enabling Internet consumer finance companies to make more accurate credit evaluations of consumers based on more detailed consumer credit information. This enables Internet consumer finance companies to make more accurate evaluations of consumers' credit status based on more detailed consumer credit information and to provide consumers with corresponding financial services and products based on the credit evaluation results, enabling the huge market potential of consumer finance to be continuously developed. Therefore, the construction of a more complete credit information system through the diverse information collection ports of the Internet platform and the accurate evaluation of consumers' credit status based on this system can reduce the risk of Internet consumer finance companies and better meet consumers' demand for financial services, thus promoting the effective allocation of financial resources, as shown in Figure 1.

As an effective tool for centralized management of funds, financial companies are an indispensable new force in the financial system, as well as a typical nonbanking financial institution that combines finance and the real economy. The unified collection and disbursement model requires enterprise group members to establish two types of accounts in their internal or commercial banks, namely, income and expense accounts. All member companies must include all revenues within the group as required and be managed by the group's unified funds management department. The expenditure account must be funded from the revenue account, allocated according to strict procedures, and no sitting cash is allowed. The advantage of the unified collection and disbursement model is that the group has a high degree of centralized funds management authority under this model.

$$
\begin{gathered}
\Delta E_{i}=E_{s i=1}-E_{s i=2}, \\
P_{s i=1}=\frac{1+e^{\Delta E_{i} / T}}{1-e^{\Delta E_{i} / T}} .
\end{gathered}
$$

The operator can easily grasp the overall balance of the group's income and expenditure and fully understand and control the company's operation and capital operation. The finance company can achieve real-time monitoring of corporate funds and can effectively achieve fund transfer and strict control. The disadvantage of the unified revenue and expenditure model is that, due to the high concentration of rights, subsidiaries and branches increase their revenue and reduce the enthusiasm of expenditure [14]. In this model, the e-commerce companies build credit models to evaluate the credit status of consumers through the long-term accumulation of information such as their consumption records, consumption habits, and credit situation. Evolutionary computing is a computational model that simulates the principles of evolution such as survival of the fittest and elimination of the inferior. It is believed that species are constantly optimized through reproduction, mutation, and selection in a competitive environment. Analogously, in the evolutionary computational model, particles are solved by crossover, selection, and mutation to achieve the problem. In nature, population optimization algorithms based on biological behavior have been proposed by observing animals such as ant colonies, fish swarms, and bees. 


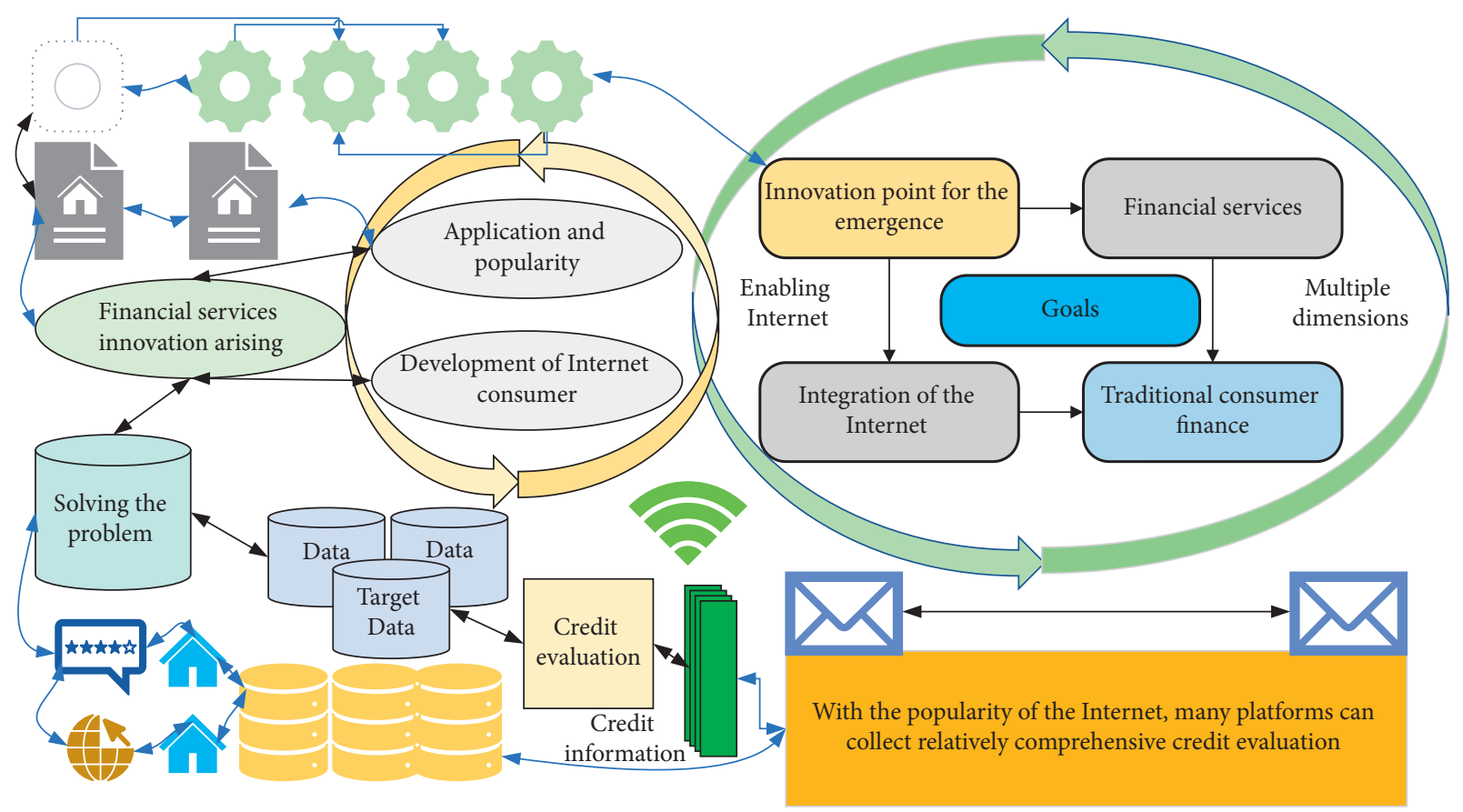

FIgURE 1: Framework of an intelligent scheduling algorithm.

$$
\begin{aligned}
x_{i d}(t-1) & =x_{i d}(t)-v_{i d}(t-1), \\
\text { s.t. } & =\left\{\begin{array}{l}
h_{i}(x)=0, i=1,2, \ldots, p, \\
g_{k}(x)>0, k=1,2, \ldots, p .
\end{array}\right.
\end{aligned}
$$

Multiobjective optimization problems have conflicting relationships with each other when computing optimal values for each objective. The reason for this is not difficult to find as the multiobjective evolutionary algorithm related to it cannot use the value comparison method to quickly search for determining the optimal solution. Considering the above needs, many experts and scholars have conducted in-depth analysis and discussion and finally proposed a simpler weighting method to deal with it, that is, matching a weight coefficient to all objectives separately. In this case, the problem is then transformed into a one-dimensional problem, so that the optimal solution can be obtained with the help of many single-objective optimization algorithms [15]. In addition, using this method does not need to focus on the population itself but only on the local population, which makes the computation process simpler and more efficient. Furthermore, the idea of neighborhood evolution in the MOEA/D algorithm gives full play to the value of similar individual information, leading to further enhancement of convergence, as shown in Figure 2. It is also related to other consumers accessing the network. The value of each consumer increases as the number of consumers accessing the network increases, which in turn promotes the development of Internet consumer financial products and services.

For business data input and maintenance, obtain the business details of interest-earning assets and interestpaying liabilities of the whole bank, maintain and update the business details according to the changes of business information, and maintain the mapping relationship between each business and the asset and liability item categories in the summary table of net interest income calculation results. For calling and loading of scenario parameters, find the corresponding interest rate types and interest rate values in the interest rate scenario parameter setting module according to the matching interest rate scenario type of each business. For a single business, after obtaining the business details and loading the interest rate scenarios, the system calculates the distribution of net interest income for the next 3 years for that business, where the time distribution within the next 2 years is divided at least month by month and placed into the corresponding time zones according to the date of interest income/expenses.

$$
\begin{aligned}
\Delta R_{1, c}(k) & =R_{\text {parallel }}^{2} \\
w & =\min _{P}\left\{\lim _{n \longrightarrow \infty} \sum_{i=1}^{n} \frac{1}{2}\left\|x_{i}-X_{P_{i}}\right\|_{2}^{2}+\chi\|P\|_{2,1}\right\} .
\end{aligned}
$$

To solve the problem of high noise in financial data, the raw data for model training is noise reduced using wavelet transform-based data preprocessing techniques, and the original wavelet denoising method is improved. The wavelet transform is used to extract useful information from the signal while removing the noisy information [16]. The wavelet transform of a signal is its transformation in the time and frequency domain. To extract useful information from the signal or to remove the noisy information, the basic wavelet is considered an analog unit. To better preserve the original information, the signal can be decomposed into a set of high and low frequencies by wavelet transform. Traditional high-pass or low-pass filters process the original signal 


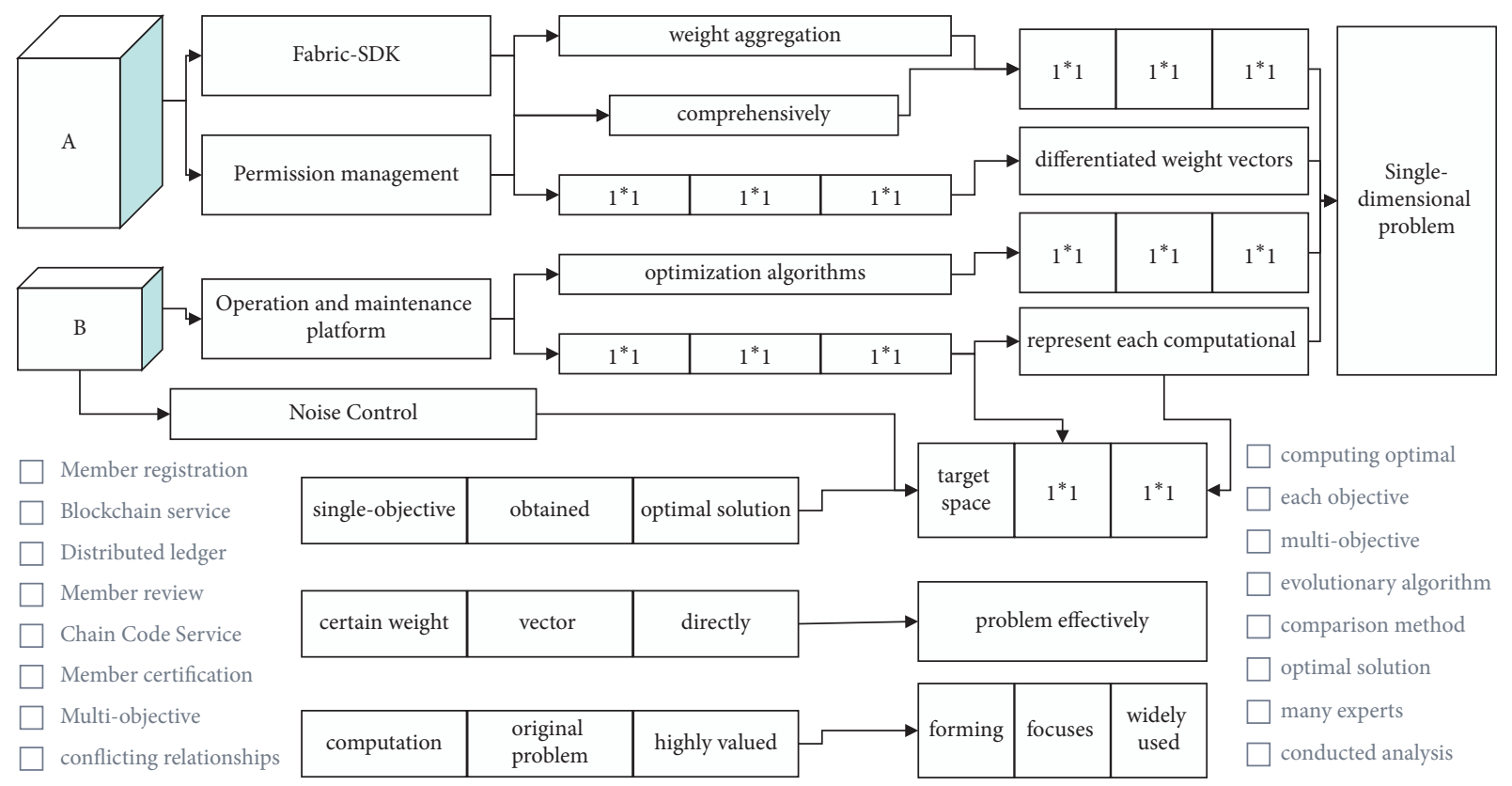

FIgURE 2: Service interface architecture.

directly without decomposing it, which may miss some usefulness of the signal information. Wavelets decompose the original signal by operations such as stretching and translating the fundamental wavelet. Then, a series of wavelet coefficients are obtained. Finally, the low-frequency information CA or the high-frequency information $\mathrm{CD}$ of the signal is obtained by a low-pass or high-pass operation, respectively.

\subsection{Optimal Design of Liquidity Management Models for} Financial Assets. The objective of liquidity risk management is to keep liquidity risk within a reasonable range, maintain sufficient liquidity reserves, and meet the 'bank's liquidity needs at a reasonable liquidity cost. Thus, the core of liquidity risk management theory is to balance the sources and uses of funds and to make the asset-liability allocation of commercial banks balanced through comprehensive management [17]. The theory holds that the management of liquidity risk should, on the premise of adhering to the three principles, combine the asset side with the liability side, identify, measure, monitor, and control liquidity risk, achieve a comprehensive evaluation of key factors such as asset size, liability situation, maturity allocation, and interest rate structure, to dynamically manage the sources and uses of funds, and ensure that commercial banks can minimize the possibility of liquidity risk. It enables commercial banks to maintain a balance of liquidity, safety, and profitability in different environments. According to this theory, commercial banks should optimize the management of asset and liability types, maturity matching, and product design and strengthen the initiative and foresight of liquidity management.

$$
f^{n}(t)=\lim _{n \longrightarrow 0} \frac{1}{h^{n}} \sum_{m=0}^{n}(-1)^{m}\left(\begin{array}{l}
n \\
m
\end{array}\right) f\left(t^{2}-m^{2} h^{2}\right) .
$$

The bank should promptly report any situation that exceeds the liquidity risk limit, establish and improve financing strategies, strengthen the management of financing channels, closely monitor the changes in trading volume and prices in the financial markets, and assess the impact of market liquidity on the 'bank's financing capacity. For Liquidity Risk Management Report and Information System, prepare liquidity risk management reports regularly to ensure that the board of directors, senior management, relevant management, and regulatory authorities remained informed of the 'bank's liquidity risk level and management status. Continuously improve the liquidity risk management system to accurately, timely, and comprehensively measure, monitor, and report the liquidity risk status [18].

$$
\operatorname{STFT}\left[A\left(t^{2}, w^{2}\right)\right]=\int_{-\infty}^{+\infty} a(\tau) g(\tau-t) e^{-j w \tau} \mathrm{d} \tau .
$$

Through centralized management of funds, the headquarter funding center unifies operations and dispatching to achieve internal resource integration and optimal allocation and maximize utility. The integrated brokerage group is managed by business lines, which are complex and diverse, with relatively abundant funds for traditional brokerage business and relatively unstable funds demand investment business. By analyzing the expected achievement of revenue targets and revenue cycles, business departments apply for funding quotas based on actual development needs, and the funding management center determines the amount of funding allocation required for the business by considering 
strategic significance, risk, and return. The huge market potential of consumer finance has been continuously developed. Therefore, through the diversified information collection ports of the Internet platform, a relatively complete credit information system is built, and an accurate evaluation of the credit status of consumers is made based on this system. In the actual operation process, it will monitor and adjust dynamically in conjunction with the profitability and will promptly reduce the scale of capital or even terminate the business if it is lower than the expected return, while it can consider increasing the investment if the profitability is good or even exceeds the expected return target. Therefore, the centralized control of capital, coordination, and transfer is conducive to achieving the scale advantage of the group, as shown in Figure 3.

At a certain stage of development, the group enterprise should be a fund management institution born out of the demand of fund management, for the enterprise internal departments, branches, subsidiaries for fund financing and settlement, effectively avoid the occurrence of scattered funds, precipitation, and other phenomena, reduce enterprise costs, and improve the efficiency of the use of funds service institutions. It facilitates the free flow and reasonable distribution of funds and helps enterprises to centralize the management mechanism and is mainly responsible for the settlement management and fund use management in the daily operation of the group.

$$
\begin{aligned}
G J_{i k}^{j \mathrm{int}} & =\sum_{i=1}^{N} G J_{k}^{j \mathrm{int}}, \\
G J_{i k}^{2} & =\frac{G J_{i k}^{j \mathrm{int}}}{\sum_{i=1}^{d} G J_{i k}^{j \mathrm{jint}}} .
\end{aligned}
$$

The centralized management of funds in large groups, using finance companies as a platform, integrates the two types of functions of external financing and fund operation. Through the mode of centralized coordination and control and moderate decentralization, a completely market-oriented cooperative relationship is introduced into the group's fund management model. It is conducive to rational allocation of funds within the group, reducing fund deposits, strengthening fund control, preventing fund risks, carrying out value-added investment business, building a platform for external capital market operation, and improving the potential returns of idle funds, as shown in Figure 4.

From the above emergency handling experience, we can see that Sheyang Agricultural and Commercial Bank's good emergency handling mechanism and swift response were the basis for the effective handling of the incident; the joint efforts of the financial management department, the provincial federation, and the local government were the key to the successful suppression of the incident; Sheyang Agricultural and Commercial Bank's good management and unconditional payment guarantee with the support of the relevant departments were the basis for the rapid suppression of the incident. The good management of Sheyang Agricultural Commercial Bank and the unconditional payment guarantee with the support of relevant departments are the fundamental reasons for this incident to be settled quickly [19].

$$
\begin{aligned}
H_{i} & =\left[h_{1}, h_{2}, \ldots, h_{N}\right]^{T} \in R^{N}, \\
D_{\varepsilon}(x(t)) & =\left[s\left(\left\|x\left(t^{2}\right)-\ell_{j 1}\right\|\right)\right] .
\end{aligned}
$$

It is worthwhile for Anhui Tianchang Rural Commercial Bank to make effective reference to these factors in its future liquidity emergency management work to effectively improve its liquidity risk emergency management and disposal level. At the same time, it is also worthwhile for Sheyang Rural Commercial Bank to learn from the initiatives it took in this incident to work with the financial management and local government to improve its reputation risk management during the crisis. The bank should consider its own liquidity risk management needs and study practical management strategies to optimize and improve the existing liquidity risk management organizational structure to make up for relevant management deficiencies and shortcomings. Possible management strategies include the following: First, giving the Asset and Liability Management Committee the necessary leadership authority for liquidity risk management in the liquidity risk management framework so that it can become a decision-making body responsible for liquidity risk management under the leadership of the board of directors or senior management of the bank.

\section{Analysis of Results}

4.1. Intelligent Scheduling Algorithm Performance Results. To validate the performance of the venture capital optimization model and intelligent algorithm proposed in this chapter, the investment risk management capability based on the root system algorithm will be verified by three investment scales. To demonstrate the superiority of the root algorithm, the particle swarm optimization (PSO) algorithm, the genetic algorithm (GA), and the artificial bee colony (ABC) algorithm are also applied to solve three cases for comparative analysis. When the root system algorithm and PSO, GA, and $\mathrm{ABC}$ are applied to solve the risk management problem, the discrete and optimized versions of their algorithms are used in the top and bottom layers of the optimization model, respectively. When computing the top-level model, the maximum number of iterations in each execution of the algorithms is 100 and the initialized population size of the algorithms is the same as 10 particles. The PSO, GA, and ABC algorithm parameters are set to the basic default parameters. For the subpopulation algorithms, the maximum number of iterations for each algorithm is 100 and the total number of initialized particles is 20 particles. It mainly forms a set of differentiated weight vectors, representing each calculation direction, to search the target space as comprehensively as possible. This method is used to find the optimal solution in all directions in the multitarget search space at the same time, and then the corresponding solution set can be obtained, which is distributed on the 


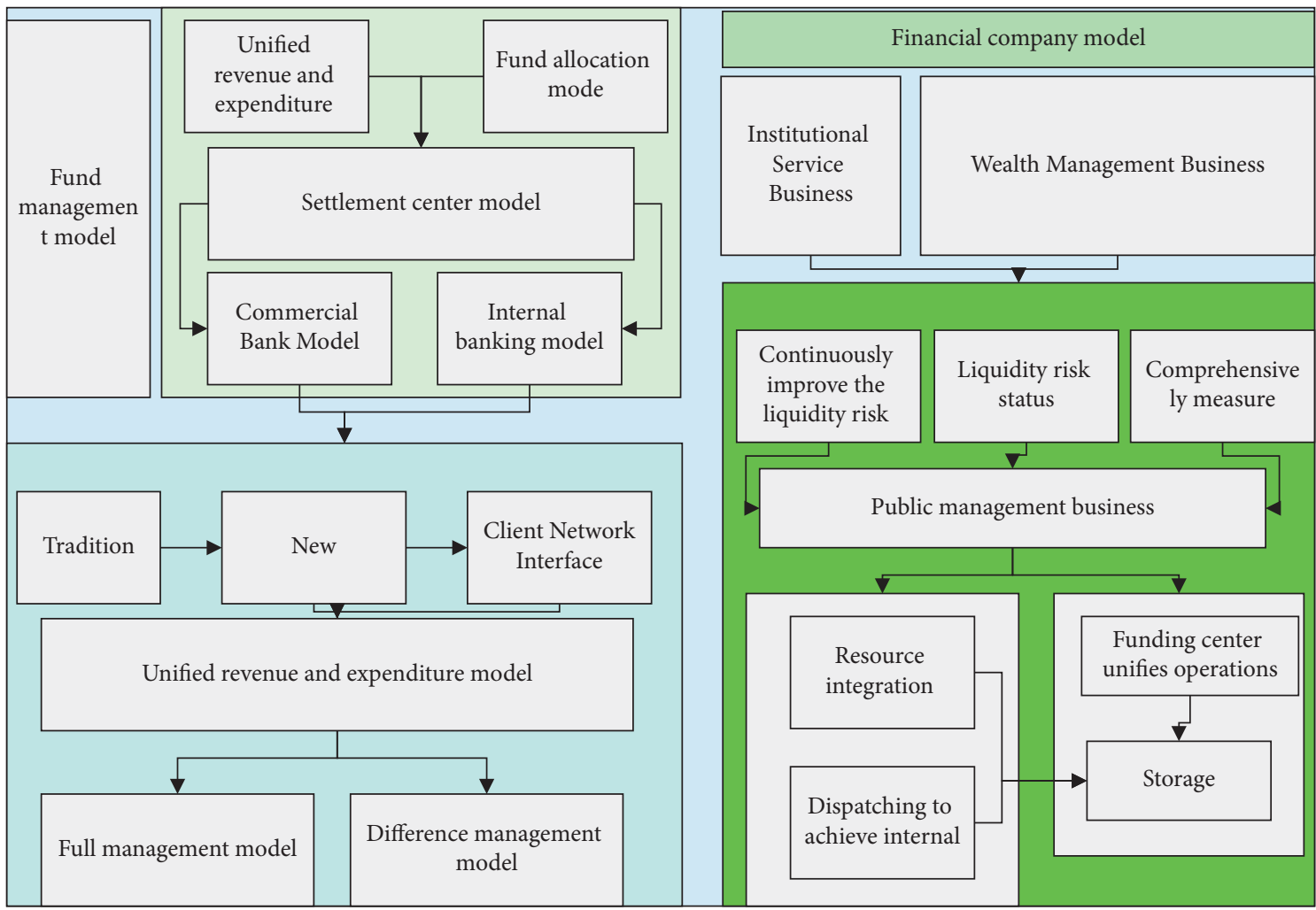

Figure 3: Classification of funds management models.

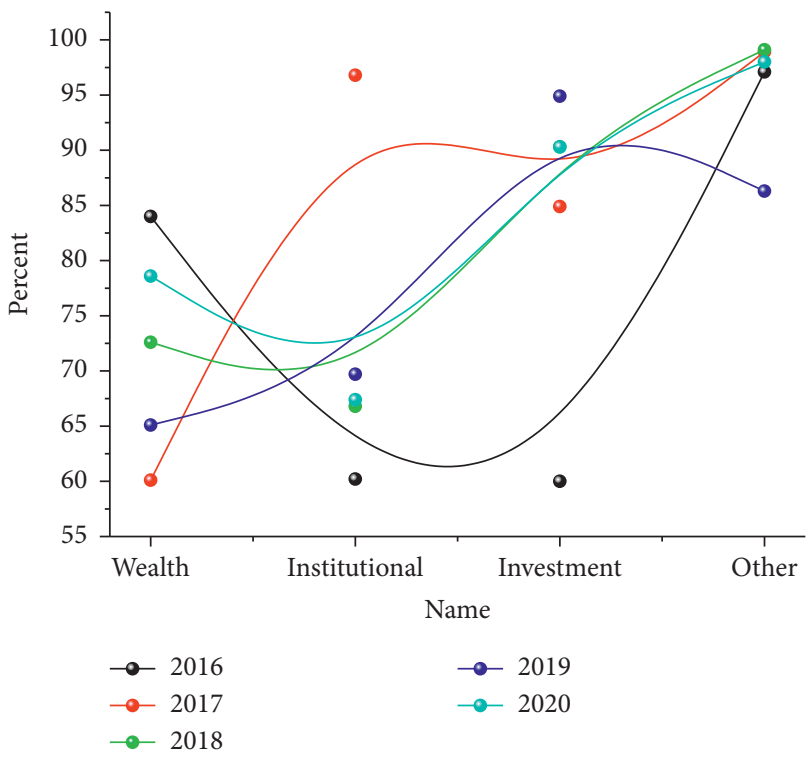

Figure 4: Distribution of business earnings.

Pareto front. Thirty experiments were conducted for each algorithm separately, and the results are shown in Figure 5.

To fully demonstrate the robustness of solving risk management effects using the root algorithm, the analysis of variance (ANOVA) of venture capital budgets based on the four intelligent algorithms on different size cases is shown in Figure 6. From the ANOVA results, the RA algorithm is more robust to larger-scale risky investment management problems. The management strategies that the bank can adopt to do a good job in emergency management include the following: first, to strengthen the liquidity risk emergency management capacity building, according to the stress risk scenario events, enrich and improve the emergency plan disposal scenarios, disposal content, and disposal arrangements; second, to establish the liquidity emergency response and disposal standards according to the nature, degree, impact, and other multidimensional factors of liquidity risk events and according to different grading. Third, we should insist on conducting emergency management drills and emergency plan testing and evaluation on an annual basis and timely enrich and improve the contents of the emergency plan according to the drills and evaluation to continuously improve the ability and efficiency of emergency management. According to its own asset allocation needs and liquidity management requirements, it will proactively do a good job in issuing interbank certificates of deposit and large certificates of deposit to broaden the channels of funding sources for liabilities; it will actively strengthen working contacts with the bank, according to its business operations and liquidity needs, and actively apply for refinancing, rediscounting, and standing borrowing facilities to further enrich financing sources.

Fourth, the bank should strengthen business cooperation with trust and investment companies, securities companies, insurance companies, and other institutions in fund settlement, cash agency, collection, and payment on behalf of the bank, as well as fund deposit, to expand the channels of fund sources. By strengthening the management of liability 


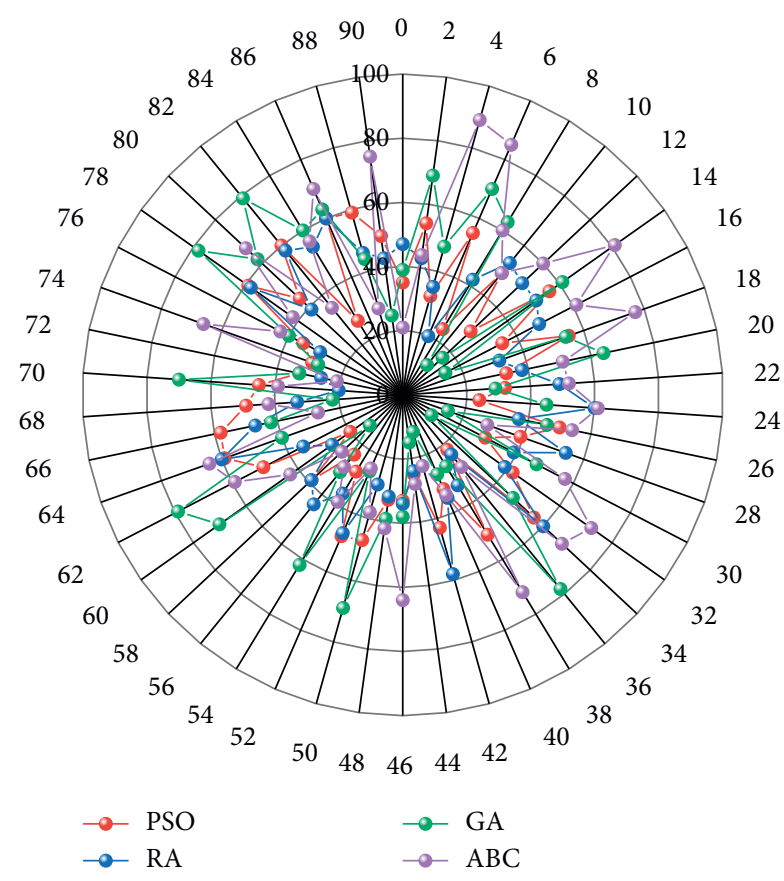

FIgURE 5: Search process.

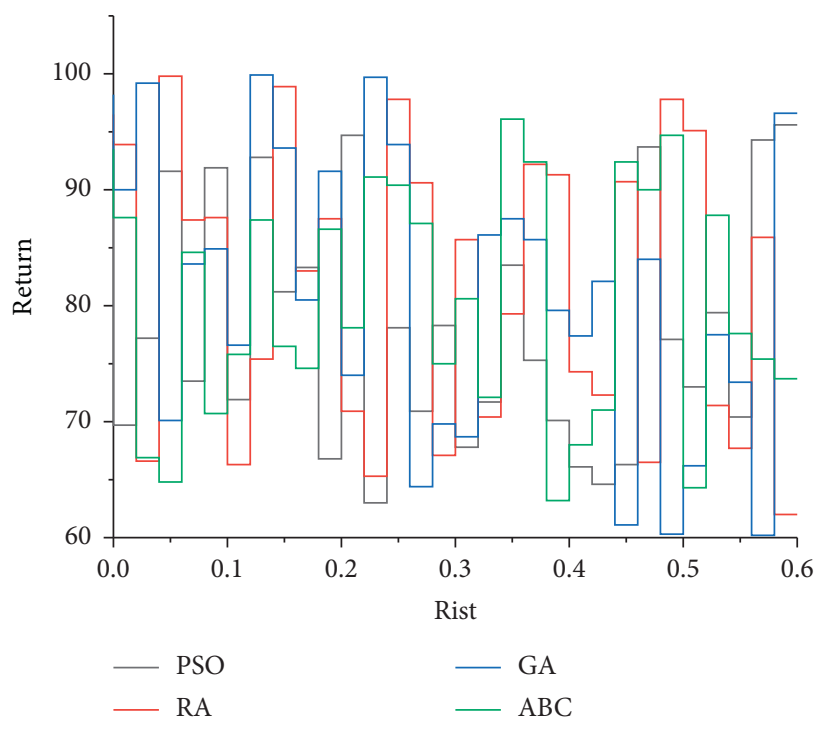

Figure 6: Portfolio model results.

business, it will enhance the security of liquidity sources and improve the level of liquidity risk management capability. Sixth, the bank should launch an investment and wealth management business as soon as possible to effectively meet the challenges of financial disintermediation. The bank should fill the "gap" in the development of investment and wealth management business as soon as possible and vigorously develop a "zero-threshold" type of wealth management business, rely on its mobile banking platform, embed the development of wealth management and investment product modules to facilitate customer service experience, and maximize the attraction and retention of customer.
For in-depth understanding of the development of the financial industry and the problems that need to be solved by financial mathematical investment, a three-objective portfolio model is proposed to achieve a reasonable mathematical description of the portfolio problem; the biological heuristic computation is systematically studied, and multiobjective optimization strategies are investigated, and various group multiobjective root algorithms are proposed accordingly; according to the characteristics of the stock forecasting problem, wavelet denoising methods are used in combination with LSTM models. The solution is carried out; according to the characteristics of risk management, a distributed risk management model is established and the RA algorithm is used for coding experiments. The risk management problem for financial mathematics is studied. Firstly, the purpose of risk management is briefly described, and many features of investment risk management are analyzed in detail. In response to these features and practical needs, a distributed decision model considering the level of investment risk is established and the RA algorithm is used for practical model optimization, and the experimental results show that the RA algorithm has excellent convergence and robustness in risk management.

4.2. Model Optimization Results. With the growth of the company's business development, it has absorbed and reorganized several brokerage firms and peers, forming a very large and comprehensive brokerage group, whose capital scale and capital volume have been expanded. There has been a general upward trend in recent years. A good corporate governance structure is a prerequisite for effective prevention and control of liquidity risk, and it appears from the bank's organizational structure that the bank's risk management system consists of the operating management, the risk management department, and the fund's management department. The operating management is responsible for the construction of the system, the risk management department is responsible for the specific work, and the fund's utilization department is responsible for the dispatch of liquidity. In the actual operation process, the liquidity risk management of the risk management department and the fund use department is led by the planning and finance department, and the main responsibility of the risk management department is to submit the relevant report data on time, while the fund use department refers to the head office business department, which is responsible for the settlement and remittance of funds daily. Under such a system, the risk management department has not fulfilled its risk control responsibilities and has become a part of the executive unit, and the management functions delegated to it by the board of directors and the senior management have not been effectively exercised, and the bank's liquidity risk management has not been given due attention.

Concerning the experience of other commercial banks in broadening their financing channels, banks need to diversify their liability business and strengthen the variety of transactions between financial markets, but the eligibility of village banks to issue bonds is restricted. The regulatory 
reporting of the bank's scope of operations stipulates that it cannot raise funds by issuing bonds or notes and so forth. In addition, it cannot participate in the interbank lending market and must interbank with financial institutions in its region or within the banking system under the authority of the main sponsor bank. This has resulted in narrow access to financing and a shortage of contingency solutions in the event of liquidity risk, as shown in Figure 7.

Fluctuations in market interest rates cause changes in the value of assets, resulting in interest rate risk. As with liquidity risk, interest rate risk that is dispersed with individual pools or different financial products or operations cannot be divested from the department and each is responsible for its own interest rate risk. Due to individual differences in the level of predicted, controlled interest rates, each is required to bear interest rate risk and cannot be hedged internally to the detriment of the efficiency and execution of overall risk control. Credit risk, also known as default risk, is a situation of default due to asymmetric information between specific operations and departments, departments and companies, companies and banks, or risks in business activities, including macro market economy, money market supply and demand, political forms, technological developments, and foreign financial market impact. Due to the partial decentralization of funds management, the current average daily agreement deposit volume, corporate account overdraft limit, liquidity reserve volume, and the actual demand cannot be accurately quantified, and the funds set aside outside the daily settlement are likely to be insufficient for advancing unexpected situations, which eventually lead to settlement failure and default resulting in credit risk. The signal can be decomposed into a set of high frequency and low frequency through wavelet transform. Traditional high-pass or low-pass filters directly process the original signal without decomposition, which may miss some usefulness of the signal information.

The performance appraisal of fund management is currently handed over to human resources appraisal, and the annual revenue of the fund-using department is used as a line to calculate the contribution rate of the headquarters' fund department on a weighted average basis. Being constrained by the fund-using departments and branches due to the revenue orientation, it is difficult for the fund management department to play its role properly, as shown in Figure 8.

It is unreasonable to assess the performance of fund management solely based on the annual rate of return and it lacks an overall strategic vision. The company's strategic goal in fund management is to fully adapt to the new market and regulatory environment, optimize resource allocation, and promote the company's multilevel, standardized, and coordinated development. Therefore, the performance assessment is not only to yield but also to consider the compliance and risk control of fund management. Funds management is firstly to regulate the operation, protect delivery, and control risk and secondly to allocate resources and maximize revenue operation and at the same time to assess whether the funds are well regulated and strategically guided in conjunction with the market and the company's strategic arrangements.

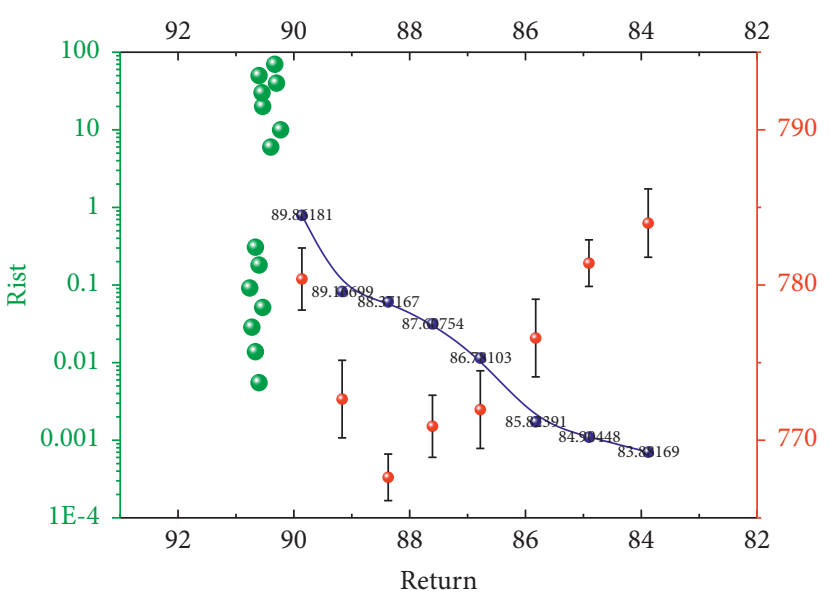

- Attention

- Management

$\rightarrow$ Exercise

FigURE 7: Return-risk-cost portfolio model.

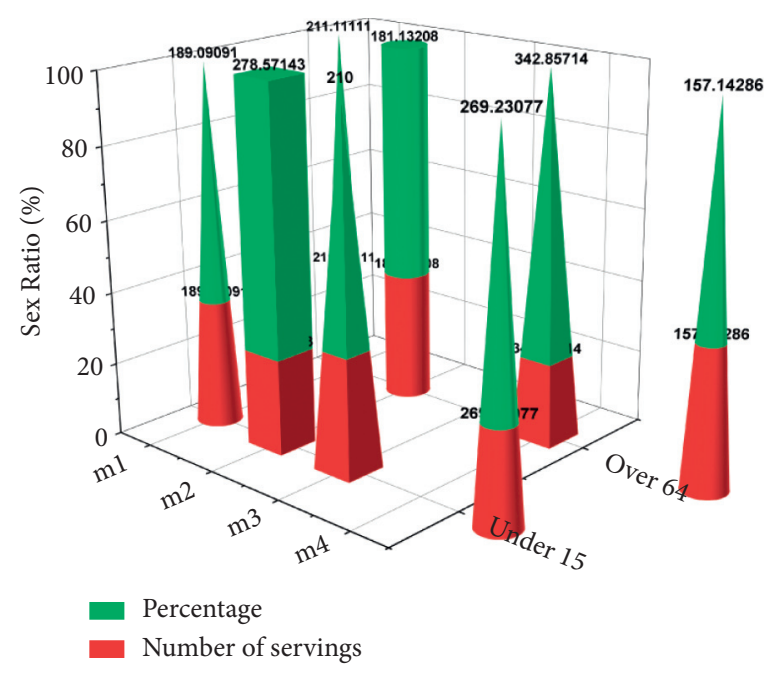

Figure 8: Comparison of overdue rates.

\section{Conclusion}

This paper examines the liquidity risk management of the bank, identifies the problems in liquidity risk management of the bank, and proposes ideas and methods to improve the liquidity risk management of the bank by using intelligent management strategies. This paper shows that, firstly, the organizational structure and management system of the bank's liquidity risk management are not working well, and it is necessary to improve the system construction and corporate governance to urge the leadership to perform their duties and improve the management effectiveness. Secondly, through the analysis of the bank's assets and liabilities, it is concluded that there is a problem in the structure of liquid assets and liabilities, and it is proposed that the key to solving this problem is to do a good job in the management of liquid assets and passive liabilities. Thirdly, the analysis of the bank's emergency handling capability of liquidity risk 
management revealed that the bank had problems such as imperfect stress test management mechanism and unstable monitoring and early warning performance. Fourth, through the study of the bank's day-to-day liquidity monitoring, the weakness of the technology system and its inability to support dynamic monitoring of liquidity risk limits was found, while making recommendations for improvement and pointing out relevant solutions to enhance the support of the technology force. Fifth, the situation of the bank's liquidity risk management personnel was discussed, and the lack of professional personnel and inadequate training of existing staff were concluded. The lack of professional personnel and the low professional competence of the existing staff are also two of the reasons affecting the low effectiveness of the bank's liquidity risk management, and relevant insights are provided on how to solve this problem.

\section{Data Availability}

The data used to support the findings of this study are available from the corresponding author upon request.

\section{Conflicts of Interest}

The authors declare that they have no conflicts of interest.

\section{References}

[1] C. Liu, Y. Feng, D. Lin, L. Wu, and M. Guo, "Iot based laundry services: an application of big data analytics, intelligent logistics management, and machine learning techniques," International Journal of Production Research, vol. 58, no. 17, pp. 5113-5131, 2020.

[2] J. Zhai and M. Bai, "Mean-variance model for portfolio optimization with background risk based on uncertainty theory," International Journal of General Systems, vol. 47, no. 3, pp. 294-312, 2018.

[3] A. Pourfarzad, "Analysis of gas sales receivables in the national Iranian gas company with an emphasis on the optimization of receivable's liquidation methods," Petroleum Business Review, vol. 2, no. 4, pp. 26-40, 2021.

[4] S. M. A. Tabei, M. Bagherpour, and A. Mahmoudi, "Application of fuzzy modelling to predict construction projects cash flow," Periodica Polytechnica: Civil Engineering, vol. 63, no. 2, pp. 647-659, 2019.

[5] L. Chen, Z. Li, M. Lv, and M. Xiong, "Intelligent prediction algorithm of economic trend index based on rough set support vector machine," Journal of Intelligent and Fuzzy Systems, vol. 38, no. 1, pp. 147-153, 2020.

[6] E. Aghamohammadzadeh and O. Fatahi Valilai, "A novel cloud manufacturing service composition platform enabled by Blockchain technology," International Journal of Production Research, vol. 58, no. 17, pp. 5280-5298, 2020.

[7] C. Milana and A. Ashta, "Artificial intelligence techniques in finance and financial markets: a survey of the literature," Strategic Change, vol. 30, no. 3, pp. 189-209, 2021.

[8] R. Keller, L. Häfner, T. Sachs, and G. Fridgen, "Scheduling flexible demand in cloud computing spot markets," Business \& Information Systems Engineering, vol. 62, no. 1, pp. 25-39, 2020.

[9] M. Steinrücke and W. Albrecht, "Integrated supply chain network planning and financial planning respecting the imperfection of the capital market," Journal of Business Economics, vol. 88, no. 6, pp. 799-825, 2018.

[10] A. Thakkar and K. Chaudhari, "A comprehensive survey on portfolio optimization, stock price and trend prediction using particle swarm optimization," Archives of Computational Methods in Engineering, vol. 28, no. 4, pp. 2133-2164, 2021.

[11] A. Yousefi and M. S. Pishvaee, "A fuzzy optimization approach to integration of physical and financial flows in a global supply chain under exchange rate uncertainty," International Journal of Fuzzy Systems, vol. 20, no. 8, pp. 2415-2439, 2018.

[12] A. Rep, K. Žager, and C. Oliveira, "The role of firm characteristics in voluntary disclosure of IC information and its importance for high-tech companies," Journal of Information and Organizational Sciences, vol. 43, no. 2, pp. 185-209, 2019.

[13] S. Gundes, N. Atakul, and F. Buyukyoran, "Financial issues in construction companies: bibliometric analysis and trends," Canadian Journal of Civil Engineering, vol. 46, no. 6, pp. 329-337, 2019.

[14] D. Mao, Z. Hao, F. Wang, and H. Li, "Novel automatic food trading system using consortium blockchain," Arabian Journal for Science and Engineering, vol. 44, no. 4, pp. 34393455, 2019.

[15] S. Mousavi, A. Esfahanipour, and M. H. Fazel Zarandi, "A modular Takagi-Sugeno-Kang (TSK) system based on a modified hybrid soft clustering for stock selection," Scientia Iranica, vol. 28, no. 4, pp. 2342-2360, 2021.

[16] S. A. Hasheminejad, M. Bagherpour, S. Nouri, and M. S. Pishvaee, "Developing a hybrid intelligent system for optimizing syndicated venture capital portfolios," Journal of Intelligent and Fuzzy Systems, vol. 37, no. 5, pp. 6483-6497, 2019.

[17] K. Elena, "Review of methods and tools for intellectual property analysis of public sector entities," Journal of Corporate Finance Research, vol. 14, no. 3, pp. 63-89, 2020.

[18] M. Kohansal, A. Sadeghi-Mobarakeh, and S. D. Manshadi, "Strategic convergence bidding in nodal electricity markets: optimal bid selection and market implications," IEEE Transactions on Power Systems, vol. 36, no. 2, pp. 891-901, 2020.

[19] D. Mattyasovszky-Philipp and B. Molnár, "An architectural approach to cognitive information systems," Acta Polytechnica Hungarica, vol. 17, no. 2, pp. 237-253, 2020. 